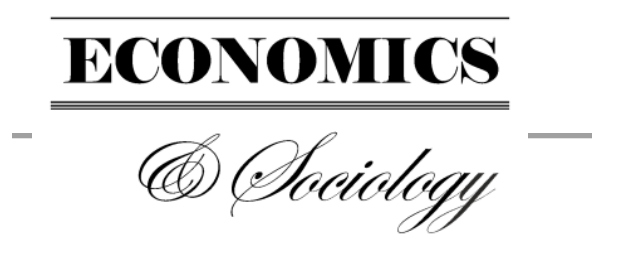

Máté, D., Sarihasan I., Popp, J., \& Oláh, J. (2018). The Role of Regional Differences in Immigration: The Case of OECD Countries. Economics and Sociology, 11(3), 190-206. doi:10.14254/2071-789X.2018/11-3/12

\author{
Domicián Máté, \\ University of Debrecen, \\ Faculty of Economics and Business, \\ Debrecen, Hungary, \\ E-mail: \\ mate.domician@econ.unideb.hu
}

\author{
Imran Sarihasan, \\ University of Debrecen, \\ Károly Ihrig Doctoral School \\ Debrecen, Hungary, \\ E-mail: \\ imran.saribasan@econ.unideb.hu
}

\section{József Popp,}

University of Debrecen,

Faculty of Economics and Business,

Debrecen, Hungary,

E-mail:

popp.jozsef@econ.unideb.bu

\section{Judit Oláh,}

University of Debrecen,

Faculty of Economics and Business,

Debrecen, Hungary,

E-mail: olah.judit@econ.unideb.hu

Received: April, 2018

1st Revision: May, 2018

Accepted: August, 2018

DOI: $10.14254 / 2071-$

789X.2018/11-3/12

JEL Classification: K37, J21, $\mathrm{J} 15$

\section{THE ROLE OF REGIONAL DIFFERENCES IN IMMIGRATION: THE CASE OF OECD COUNTRIES}

\begin{abstract}
Despite physical, cultural, economic and other obstacles, millions of people have recently emigrated from one country to another in search of a better life. Consequently, the importance of this research topic has grown over time. Analysis of this regional approach is based on the OECD censuses, and its unique Database on Immigrants (DIOC), which makes it possible to generate a wide variety of cross-tabulations on the characteristics of asylum-seekers by the country of their birth. The aim of this study is to contribute to literature by analysing the role of regional differences in migration more closely in terms of the importance of migration regulation policies in the OECD countries. According to the results based on Binary Logistic (Logit) and Linear (OLS) Regression models, the educational attainment, age, sex and the place of birth of migrants are related in different ways to their region of origin. Moreover, male migrants are more skilled than females, migrants who are more educated are older than the less skilled, and foreign-born migrants seemed to be older than native-born migrants. There is also additional evidence suggesting that different regions and countries might follow different policies and norms for admission of migrants. Therefore, forthcoming migration governance programs that aim to facilitate the labour market integration of migrants should also take into consideration their regional characteristics.
\end{abstract}




\section{Introduction}

Regions of the world account for different proportions in the global number of migrants. The origin of international migrants has become increasingly diversified over the past two decades (United Nations, 2017). Asia and Europe hosted over $60 \%$ of all international migrants worldwide in 2017, with nearly 80 million living in Asia and 78 million in Europe. North America hosted the third largest number of international migrants (58 million), followed by Africa (25 million), Latin America and the Caribbean (10 million), and Oceania (8 million) (UN, 2017). Asia, Europe and North America accounted for over $85 \%$ of the increase in the number of international migrants between 1990 and 2017. Thus, between 2010 and 2017, Africa experienced the second fastest annual growth, with the average of 1.1 million per annum (Figure 1).

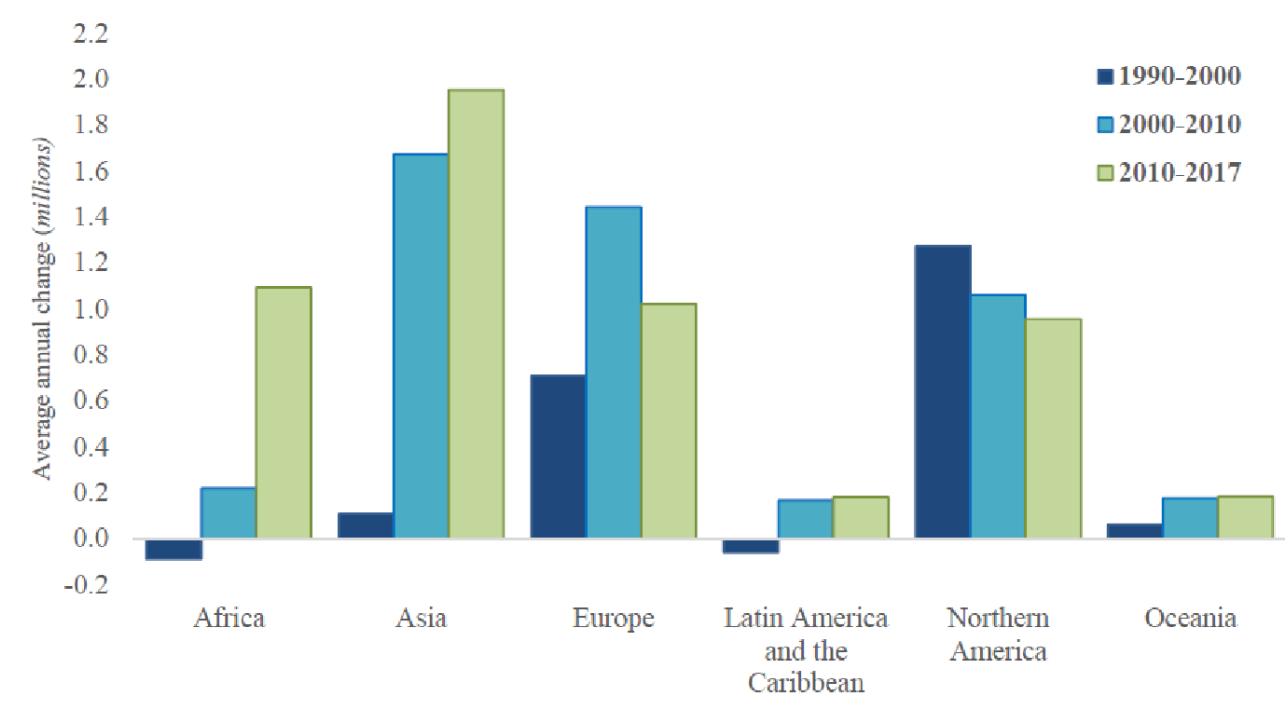

Figure 1. Average annual change in the number of international migrants by major regions of origin, 1990-2017 (millions)

Source: Authors' own compilation based on United Nations (UN, 2017).

The latest wave of immigration in the post-crisis period (2010-2015) is unlike previous waves in terms of skill and origin structure. Burzynski, Docquier, \& Rapoport (2018) have shown that the welfare effects of immigration are very heterogeneous across skill groups, countries of destination, and immigration waves. For instance, the latest wave period of immigration is less skilled and brings fewer benefits. The welfare impact of recent migration flows have been beneficial for $69 \%$ of the non-migrant OECD residents, and for $83 \%$ of nonmigrant citizens in 22 richest OECD countries. The leading beneficiaries are mainly traditional immigration countries; their gains are extensive due to the entry of immigrants from non-OECD countries (Aubry, Burzyński, \& Docquier, 2016).

There are various economic, social and physical reasons why people emigrate and they can usually be classified into push (negative incentives) and pull (positive) factors (Bodvarsson \& Van den Berg, 2013). The main economic reason for choosing to be a migrant is to seek an improved life by finding a job, and the driving forces of migration are higher wages, human security and work opportunities (Castles, 2013). The economic push factors tend to be the exact opposite of the pull factors that are associated with the area of destination (overpopulation, insufficient number of jobs, low wages etc.). However, other social reasons, i.e. civil and political rights, religious freedom, law and order, social mobility, personal 
safety, and peace, together with other attractive environmental factors (climate, seaside location etc.) all make a destination country attractive to potential immigrants.

These economic, political and social incentives exist worldwide, thus influencing international migration over recent decades (Ozgur \& Deniz, 2014). The economic characteristics of migrants and their motivations for moving vary by age group and by migrant status (Philip, Macleod, \& Stockdale, 2013). Several studies (McInnis 1971; Millington, 2000 etc.) demonstrate there is a positive relationship between the age of responsiveness and the economic gains from migration. Hence, younger migrants have great adaptability to new challenges when entering the labour market of a destination country. Moreover, regional differences - including wage and age disparities etc. - can affect migration as well (Hunt, 2012). Essentially, people migrate from low-income to high-income regions, which increases the mobility cost of migration. This presumption focuses almost exclusively on the size and direction of population flows across regions (Borjas, Bronars, \& Trego, 1992). Thus, the relationship between migration, age, education, segregation and distance have been discussed in many economic studies (Schwartz, 1976; Mueser, 1989; Iceland, 2017 etc.). Although migrants typically transfer from lower to higher income regions, migration flows increase with higher education and reduce with aging. Nevertheless, the economic impact of migration depends on the number and the education level of migrants and also on how well education of migrating individuals matches their future occupations (Quinn \& Rubb, 2005).

The skill- and origin-mix of migration to the OECD has evolved over time. Meanwhile, many OECD countries have been attempting to attract qualified human resources from abroad, since knowledge-based and progressive economies need to sustain their economic growth (Dumont \& Lamaitre, 2005). It is beneficial for these countries to acquire migrants who have solid education and well-developed skills in order to improve their economic performance, since it has been widely acknowledged that education and skills together are the major sources of economic prosperity (Flisi, Meroni, \& Vera-Toscano, 2016). These intentions are highly dependent on the time frame involved, i.e. education has a greater influence on long-term migration decisions (Williams et al., 2018). Moreover, the influence of migration may lead to changes in the average levels of education in destination countries and generate educational externalities and new incentives for human capital investments (Dustmann \& Glitz, 2011).

Furthermore, each migrant is a source of personal consumption expenditure, which is also transferred among the regions. Di Giovanni, Levchenko, \& Ortega (2015) compared welfare with levels of migration from the cross-country global analysis perspective, and found that natives in those countries (Canada, Australia) that received high levels of migration are better off due to a greater product variety available in consumption and as intermediate inputs. Meanwhile, in the short run, skilled and unskilled natives tend to experience welfare changes with opposite signs. Initial studies have discussed the process of understanding the relationships between trade, migration, and regional changes (Fournier, 1989). Meanwhile, education systems and social policies are not similar across regions, while socioeconomic status and ethnocultural arrangements of immigrants diverge considerably. Such characteristics of migration may be associated with regional differences in the education outcomes. Migration also has economic, social and cultural consequences for both the origin and the destination countries. This phenomenon is signalled by the absence of social barriers, participation in mainstream institutions, intermarriage with host country natives, and degrees of self-identification by immigrants as natives (Beck, Corak, \& Tienda, 2012).

The aim of this study is to contribute to literature by analysing the role of regional differences of migration more closely in terms of the importance of migration regulation policies in the OECD countries. The significance of our regional perspective is to explain the complexity of migration characteristics in different societies, taking into account spatial and 
geographic aspects. Considering the consequences of population distribution, age, and gender structure etc. can be compatible with the integration purposes of migration policies (Findlay $\&$ Mulder, 2015). Assuming also that common migration policies do not work properly, there is no unique solution for social and economic problems of migration in terms of inequalities. The effects of these inequalities in migration on the places of origin and destination are also influenced by a process called migration selectivity. Hence, certain individuals are more likely to migrate, based on their personal and sociodemographic characteristics.

The rest of this paper is organized as follows. The next (1) section summarizes the brief conceptual framework of migration theories with a regional perspective. Then, in section 2, logistics (Logit) and linear (OLS) regression analyses are carried out with cross-country statistics in order to investigate how gender, aging, place of birth, and educational attainment differences are related to regional characteristics of migrants. Finally, based on these results, the paper ends with some policy implications and conclusions (Section 4). However, our motivation is not only to suggest a feasible point of reference for researchers, to enhance the effectiveness of policies, to reduce the negative consequences of modern slavery, but also to outline further research directions in this international perspective related to the quality of migration regulation across countries in the interests of human development over time.

\section{Literature review}

The notion of migration is commonly understood as a movement from one location to another for the purpose of either temporary or permanent settlement. This may involve longdistance traveling, across or within the borders of a country from one region to another with a distinctly different cultural, political or social etc. environment (Biswas, McHardy, \& Nolan, 2005). The development of migration occurs when an individual decides that it is preferable to move rather than to stay, and where the difficulties of moving seem to be more than offset by the expected rewards. Population movements are responses to distinct conditions and related incidents, which people encounter both in places of origin and destination.

The early theories of migration were mostly focused on domestic migration, and were closely related to location models from regional economics and the economics of geography. E. G. Ravenstein first developed the 'law of migration', which classified migrants by the distance of relocation (Ravenstein, 1885). According to Ravenstein's laws of migration, most migrants move only a short distance and usually to large cities that grow rapidly and tend to be populated by migrants from nearby rural areas. Thus women are more likely to migrate than men, the out-migration is inversely related to in-migration, and a major migration wave will generate a compensating counter wave (Greenwood, 1997).

In this early approach, local migrants moved within the country, or only from the country of their birth to border countries (Koser \& Salt, 1997). Therefore, a series of analyses attempted to explain and predict migration patterns both within and between nations. The basic and additional laws of migration subsequently emerged to serve as the starting point for all serious models of migration patterns. One of these laws relating to the gender gap asserted that short-distance migrants far outnumbered longer distance ones, and women dominated within countries. The outcome of these tendencies led to an inverse relationship between the volume of migration and the distance between the home and destination countries.

The theoretical background to international migration is mainly grounded in the consumption approach favoured by urban and regional economists and which focuses primarily on domestic migration. Greenwood (1993) points out that by the early 1980s, the 'equilibrium' perspective on migration suggested people migrate to take advantage of regional income differences. The elementary idea behind this perspective is that people migrate to adjust their consumption to frequent changes in incomes, prices, the supply of 
goods and services and their utility functions etc. (Rosen, 1974). The notion that people migrate in response to spatial differences in amenities was also proposed by Tiebout (1956), who argued that an important factor explaining why people move from one locality to another is differences in the quality of public goods, such as police and fire protection, education, hospitals, courts and other facilities. Nevertheless, the idea has not been applied to the studies of international migration in terms of its regulated nature and the relatively higher costs of international movement.

Thus, the empirical results from national analyses only contributed to the verification of migration theories, and to identifying potential differences between (inter)national determinants of migration, so as to become the groundwork for regional economic policies (Jandová \& Paleta, 2015). Nevertheless, according to the 'push and pull' general theory of migration, immigration is determined by a summarized comparison of a wide range of positive factors in destination countries and various negative ones in the original place of residence (Rahmandoust, 2011). In other words, migration is selective and tends to consider positive (pull) factors which occur in the migration destination attracting migrants to the country of destination (Kainth, 2009). Moreover, negative (push) reasons also occur, which in some circumstances drive migrants to leave their countries of origin to destination regions. Meanwhile, in the sociological literature on migration, the role of the community of family and friends at the destination is often referred to as a relationship. The banding together of previous migrants from a similar ethnic or regional background is also referred to as a migrant network, based on the linguistic similarity between specific areas (Chiswick \& Miller, 2014). Evidence also supports the idea that immigrants tend to concentrate where earlier nationals have settled because the cost of adapting to a novel society is mitigated by the presence of residents familiar with both the source and destination country cultures. The level of spatial mobility is larger, ceteris paribus, when the verbal and cultural environment in the destination country is familiar (Rephann \& Vencatasawmy, 2000).

In our opinion, no unique immigration theory has yet been devised which can completely explain regional migration disparities. Thus, there is still a big gap between theory and empirical evidence, and much needs to be done on the theoretical side of this literature, as well. One of the greatest challenges to migration theorists is to organize all hypothetically relevant factors into one coherent framework that will specify their interaction with each other in an empirically testable form and thereby serve as a guide for future research. Consequently, more studies are needed using many econometric models, data sets, time periods, countries, and replications of existing studies before economists can have enough confidence in the results of their own statistical studies of immigration.

\section{Data and methodological approach}

This research uses the Database on Immigrants in OECD Countries (DIOC) which provides detailed information on the census data of immigrants (OECD, 2018). This unique database makes it possible to generate an extensive variety of cross-tabulations on the characteristics of the migrant inhabitants in OECD countries by their country of birth. The latest available release includes a specific area covering age, gender, nationality, place of birth and duration of stay etc.

The estimations are mainly based on binary logistic (Logit) regression models (see Equation 1, 2, 3, 4, 5 and 6) that are frequently used to apply to a binary dependent variable of different regions. The Logit regression method was first developed by Cox (1958) to estimate the probability of a binary response based on one or more predictor (or independent) variables. In order to analyse whether educational attainment, age, sex and the place of birth 
of migrants relate differently to their region of birth the following models are tested in each case for the migrants observed $\varepsilon_{i}$ :

$$
\begin{aligned}
& \text { DAfrica }_{i}=\beta_{o}+\beta_{1} \text { Edu }_{i}+\beta_{2} \text { Age }_{i}+\beta_{3} \text { DSex }_{i}+\beta_{4} \text { DFborn }_{i}+\varepsilon_{i} \\
& \text { DAsia }_{i}=\beta_{o}+\beta_{1} \text { Edu }_{i}+\beta_{2} \text { Age }_{i}+\beta_{3} \text { DSex }_{i}+\beta_{4} \text { DFborn }_{i}+\varepsilon_{i} \\
& \text { DEurope }_{i}=\beta_{o}+\beta_{1} \text { Edu }_{i}+\beta_{2} \text { Age }_{i}+\beta_{3} \text { DSex }_{i}+\beta_{4} \text { DFborn }_{i}+\varepsilon_{i} \\
& \text { DN_America }_{i}=\beta_{o}+\beta_{1} \text { Edu }_{i}+\beta_{2} \text { Age }_{i}+\beta_{3} \text { DSex }_{i}+\beta_{4} \text { DFborn }_{i}+\varepsilon_{i} \\
& \text { DOceania }_{i}=\beta_{o}+\beta_{1} \text { Edu }_{i}+\beta_{2} \text { Age }_{i}+\beta_{3} \text { DSex }_{i}+\beta_{4} \text { DFborn }_{i}+\varepsilon_{i} \\
& \text { DS\&C_America }_{i}=\beta_{o}+\beta_{1} \text { Edu }_{i}+\beta_{2} \text { Age }_{i}+\beta_{3} \text { DSex }_{i}+\beta_{4} \text { DFborn }_{i}+\varepsilon_{i}
\end{aligned}
$$

The dependent variables are dummies distinguished by the migrants' different region of birth, i.e. DAfrica is $=1$ if the migrant is born in Africa, $0=$ otherwise. Respectively, DAsia refers to Asia, DEurope to Europe, DN_America to North America, DOceania to Oceania, and DS\&C_America indicates South and Central America. The first independent variable is (Edu), where the detailed educational levels (1-6) are based on the International Standard Classification of Education (ISCED) as defined by UNESCO (2011). The next control variable is (Age), which is divided into the following age group categories: $1=0-14$; $2=15-24 ; 3=25-34 ; 4=35-44 ; 5=45-54 ; 6=55-64 ; 7=65+$. The (DSex) dummy notes the gender differences; namely, 1 if the migrant is female, 0 if male. The subsequent control dummy variable (DFborn) indicates whether the migrant is foreign- or native-born. According to the OECD (OECD, 2017), foreign-born immigrants include all those who have ever migrated from their country of birth to their current country of residence. Thus, a native-born citizen of a country is one whose migrant parents' place of birth is the host country. $(\varepsilon)$ is the error term.

Based on the previously reported (1-6) Equations, the current study forms the following hypotheses:

H1: African migrants are less likely to be educated, older, foreign-born and female than other migrants.

H2: Asian migrants are less likely to be educated, older, foreign-born and female than other migrants.

H3: European migrants are less likely to be educated, older, foreign-born and female than other migrants.

H4: North American migrants are less likely to be educated, older, foreign-born and female than other migrants.

H5: Oceanian migrants are less likely to be educated, older, foreign-born and female than other migrants.

H6: South and Central American migrants are less likely to be educated, older, foreign-born and female than other migrants.

In order to exemplify the validity of our results, and verify that educational attainment, and age of migrants relate differently to their region of birth, additional methodologies are needed to clarify the regional characteristics of migration. For instance, linear OLS regressions. Consequently, a linear (OLS) regression model is used to highlight the regional differences among our evaluations. 
$E d u_{i}=\beta_{o}+\beta_{1}$ Age $_{i}+\beta_{2}$ DSex $_{i}+\beta_{3}$ DFborn $_{i}+\beta_{4}$ DAfrica $_{i}+\beta_{5}$ DAsia $_{i}+$ $\beta_{6}$ DEurope $_{i}+\beta_{7} D N_{-}$Anerica $_{i}+\beta_{8}$ DOceania $_{i}+\varepsilon_{i}$

Age $_{i}=\beta_{o}+\beta_{1}$ Edu $_{i}+\beta_{2}$ DSex $_{i}+\beta_{3}$ DFborn $_{i}+\beta_{4}$ DAfrica $_{i}+\beta_{5}$ DAsia $_{i}+$ $\beta_{6}$ DEurope $_{i}+\beta_{7}$ DN_Anerica $_{i}+\beta_{8}$ DOceania $_{i}+\varepsilon_{i}$

Note that the South and Central American region variable was omitted in order to control and avoid the 'dummy-trap' problem. The dummy variable trap is a phenomenon in which the independent variables are multicollinear and two or more variables are highly correlated, i.e. one variable can be predicted from the others. Moreover, based on Equations 7 and 8, the following forms of the hypotheses can be also verified:

H7: Female migrants are less educated than males.

H8: Foreign-born migrants are less educated than native-born migrants.

H9: Migrants that are more educated are older than less educated migrants.

H10: Male migrants are older than females.

H11: Foreign-born migrants are younger than native-born migrants.

\section{Conducting research and results}

Table 1, 2 and 3 represent the corresponding results of our estimations in each model. In order to take account of the effect of regional differences we focus separately on migrants by region of birth and assume that they have different educational, age, gender and origin of birth characteristics compared to the other regions. In all observed logistic (Logit) regression models (see Tables 1 and 2), the dependent variable indicates the migrants' region of birth. At the bottom sections of these tables are the proportion of variances explained by the predictors (measured by Cox and Shell's, and Nagelkerke's pseudo $\mathrm{R}^{2}$ ). However, the $\mathrm{R}^{2}$ statistics of these models are relatively small, thanks to a large number of observations. According to the Omnibus (F-test) and HL-tests, the explained variances in a set of data are significantly greater than the unexplained variance.

In the case of Africa and Europe, we found a significant negative relationship between the educational attainment and the region of birth. Although the effect of education does not seem to be large in North, South and Central America and Oceania, in these models there was a positive correlation. In other words, African, Asian and European migrants tend to be less educated than others. In the case of Africa, Asia, Oceania, and South and Central America age negatively associated with region of birth variables, which indicates that in these regions migrants are more likely to be younger than the other regions. Nevertheless, if there are two migrants and one of them comes from Europe or North America, he/she will be significantly older than the other.

Moreover, gender differences can be found in only a few cases. African migrants tend to be male, with European and South and Central Americans tending to be female. Measuring the origin of birth differences, we can also claim that Asian, and South and Central American migrants are significantly more likely to be foreign-born. From the results it can be claimed that North Americans asylum seekers and migrants from Oceania tend to be native-born. Although, the strong H1, H2, H3, H4, H5 and H6 hypotheses should be rejected, based on the results it can be claimed that the educational attainment, age, sex and the place of birth of migrants relate differently to their region of birth. 
Table 1. Results of the binary logistic (logit) regressions in the examined OECD countries in Africa, Asia and Europe

\begin{tabular}{|c|c|c|c|c|c|c|c|c|c|}
\hline Dependent & & DAfrica & & & DAsia & & & DEurope & \\
\hline Independent & Beta & Wald & $\operatorname{EXP}(B)$ & Beta & Wald & $\mathrm{EXP}(\mathrm{B})$ & Beta & Wald & $\operatorname{EXP}(B)$ \\
\hline Constant & -20.98 & 0.001 & 0 & -4.281 & $1072.6^{* * *}$ & 0.013 & 1.493 & $1259.2 * * *$ & 4.452 \\
\hline Edu & -0.011 & $31.6 * * *$ & 0.989 & 0.001 & 0.238 & 1.001 & -0.008 & $21.2 * * *$ & 0.991 \\
\hline Age & -0.027 & $215.9 * * *$ & 0.974 & -0.012 & $40.8 * * *$ & 0.988 & 0.038 & $539.3 * * *$ & 1.039 \\
\hline DSex & -0.048 & $50.4 * * *$ & 0.953 & -0.005 & 0.471 & 0.995 & 0.016 & $6.7 * * *$ & 1.016 \\
\hline DFborn & 20.011 & 0.001 & 0 & 3.138 & $582.6 * * *$ & 23.04 & -2.503 & 3893.2 & 0.081 \\
\hline Observations & & & & & 491813 & & & & \\
\hline Cox and Shell $\mathrm{R}^{2}$ & & 0.06 & & & 0.04 & & & 0.13 & \\
\hline Nagaike $\mathrm{R}^{2}$ & & 0.08 & & & 0.06 & & & 0.18 & \\
\hline Omnibus-test & & $2766.5^{* * * *}$ & & & $1984.6 * * *$ & & & $6346.1 * * *$ & \\
\hline HL-test & & $103.2 * * *$ & & & $32.87 * * *$ & & & $212.6^{* * * *}$ & \\
\hline
\end{tabular}

Source: Authors' own compilation, based on (OECD, 2018)

Notes: Heteroscedasticity robust Wald-statistics are in parentheses. Letters in the upper index refer to significance: ***: significance at 1 per cent, ${ }^{* *}: 5$ per cent, *: 10 per cent. P-values without an index mean that the coefficient is not significant even at the 10 per cent level. HL: Hosmer and Lemeshow $\chi^{2}$ test.

Table 2. Results of the binary logistic (logit) regressions in the examined OECD countries in North America, Oceania and South and Central America

\begin{tabular}{|c|c|c|c|c|c|c|c|c|c|}
\hline Dependent & & DN_Americ & & & DOceania & & & $S \& C \_$Amer & \\
\hline Independent & Beta & Wald & $\operatorname{EXP}(\mathrm{B})$ & Beta & Wald & $\operatorname{EXP}(B)$ & Beta & Wald & $\operatorname{EXP}(B)$ \\
\hline Constant & -3.417 & $1423.1 * * *$ & 0.033 & -2.755 & $1719.3 * * *$ & 0.064 & -3.075 & $1870.3 * * *$ & 0.046 \\
\hline Edu & 0.017 & $6.6 * *$ & 1.017 & 0.029 & $56.4 * * *$ & 1.030 & 0.013 & $33.2 * * *$ & 1.013 \\
\hline Age & 0.034 & $33.1 * * *$ & 1.035 & -0.010 & $8.2 * * *$ & 0.990 & -0.010 & $23.6 * * *$ & 0.990 \\
\hline DSex & -0.022 & 0.995 & 0.978 & -0.001 & 0.003 & 0.999 & 0.046 & $35.6^{* * *}$ & 1.047 \\
\hline DFborn & -0.834 & $113.9 * * *$ & 0.434 & -0.246 & $16.3^{* * *}$ & 0.782 & 1.390 & $402.1 * * *$ & 4.016 \\
\hline Observations & & & & & 491813 & & & & \\
\hline Cox and Shell $\mathrm{R}^{2}$ & & 0.01 & & & 0.01 & & & 0.01 & \\
\hline Nagaike $\mathrm{R}^{2}$ & & 0.02 & & & 0.02 & & & 0.02 & \\
\hline Omnibus-test & & $134.3 * * *$ & & & $76.98 * * *$ & & & $711.5 * * *$ & \\
\hline HL-test & & $9.123 *$ & & & $97.25 * * *$ & & & $7.854^{*}$ & \\
\hline
\end{tabular}

Source: Authors' own compilation, based on (OECD, 2018)

Notes: Heteroscedasticity robust Wald-statistics are in parentheses. Letters in the upper index refer to significance: ***: significance at 1 per cent, **: 5 per cent, *: 10 per cent. P-values without an index mean that the coefficient is not significant even at the 10 per cent level. HL: Hosmer and Lemeshow $\chi^{2}$ test. 
Measuring the effects of aging, gender, and region of birth differences on educational attainment of migrants (in Models 1 and 2), based on Equation 7, can also provide efficient empirical tools for regional migration policy reforms. Thus, using Equation 8 in our regression models ( 3 and 4 ), the influence of these examined variables on the age of immigrants is also tested in a regional context. In the case of Models 2 and 4 we only add the variables which were significant in Models 1 and 3; the others are omitted. However, the adjusted $\mathrm{R}^{2}$ values are quite low because of the large number of observations $(491,813)$; the significant F-test statistics suggest that our linear regression specification should be preferred in all models. The multi-collinearity amongst the independent and control variables is tested by the variance inflation factor (VIF) in each case. The maximum values of VIF for each regression coefficient range from a low of 1.181 to a high of 1.971. This suggests that the VIF values are at acceptable (less than 10) levels (Hair, 2010). At the bottom section of Table 3, as a goodness of fit (GOF) test of our regression the Kolmogorov-Smirnov (K-S) normality tests of the non-standardized residuals are also reported, to check one of the assumptions of the linear regression.

Table 3. Results of the OLS regressions of Equations 7 and 8 in the OECD countries examined

\begin{tabular}{|c|c|c|c|c|}
\hline Independent variables & Model 1 & Model 2 & Model 3 & Model 4 \\
\hline \multirow{2}{*}{ Constant } & $3.163 * * *$ & $3.172 * * *$ & $3.885 * * *$ & $3.894 * * *$ \\
\hline & 117.981 & 306.573 & 181.981 & 136.407 \\
\hline \multirow[t]{2}{*}{ Edu } & & & $0.081 * * *$ & $0.081 * * *$ \\
\hline & & & 50.744 & 50.737 \\
\hline \multirow[t]{2}{*}{ Age } & $0.064 * * *$ & $0.064 * * *$ & & \\
\hline & 50.744 & 50.857 & & \\
\hline \multirow[t]{2}{*}{ DSex } & $-0.034 * * *$ & $-0.034 * * *$ & 0.007 & \\
\hline & $(-7.115)$ & $(-7.148)$ & 1.229 & \\
\hline \multirow[t]{2}{*}{ DFborn } & 0.008 & & $-0.101 * * *$ & $-0.101 * * *$ \\
\hline & 0.321 & & $(-3.612)$ & $(-3.611)$ \\
\hline \multirow[t]{2}{*}{ DAfrica } & $-0.057 * * *$ & $-0.058 * * *$ & $-0.043 * * *$ & $-0.041 * * *$ \\
\hline & $(-7.508)$ & $(-7.891)$ & $(-4.946)$ & $(-6.002)$ \\
\hline \multirow[t]{2}{*}{ DAsia } & $-0.031 * * *$ & $-0.031 * * *$ & -0.002 & \\
\hline & $(-4.029)$ & $(-4.293)$ & $(-0.236)$ & \\
\hline \multirow[t]{2}{*}{ DEurope } & -0.049 & $-0.051 * * *$ & $0.125 * * *$ & $0.126 * * *$ \\
\hline & $(-6.831)$ & $(-7.278)$ & 15.293 & 19.981 \\
\hline \multirow[t]{2}{*}{ DN_America } & 0.014 & & $0.148 * * *$ & $0.150 * * *$ \\
\hline & -0.71 & & 6.861 & 7.13 \\
\hline \multirow[t]{2}{*}{ DOceania } & $0.045 * * *$ & $0.044 * * *$ & -0.003 & \\
\hline & 3.706 & -3.669 & $(-0.252)$ & \\
\hline Observations & \multicolumn{4}{|c|}{491813} \\
\hline Adj. $\mathrm{R}^{2}$ & 0.06 & 0.06 & 0.07 & 0.07 \\
\hline F-test & $344.18 * * *$ & $460.77 * * *$ & $407.21 * * *$ & $651.22 * * *$ \\
\hline VIF & 1.971 & 1.821 & 1.971 & 1.181 \\
\hline \multicolumn{5}{|c|}{ Normality test of the non-standardized residuals } \\
\hline K-S test & $0.123^{* * *}$ & $0.123^{* * *}$ & $0.083 * * *$ & $0.083 * * *$ \\
\hline
\end{tabular}

Source: own compilation based on (OECD, 2018)

Notes: Heteroscedasticity robust t-statistics are in parentheses. Letters in the upper index refer to significance: ***: significance at 1 per cent, **: 5 per cent, *: 10 per cent. $\mathrm{P}$-values without an index mean that the coefficient is not significant even at the 10 per cent level.

From the regional perspective, the age and educational attainment related differently to the region of birth. For example, as we found previously, African, Asian and European 
migrants have a negative relationship with educational attainment with a high significance level in each case. In other words, these migrants are less educated than the others we examined. The majority of the population in Africa have a very low standard of education and only $25 \%$ of the population achieve an acceptable standard in the education system (Reed \& Andrzejewski, 2010). Thus, misunderstanding or ignorance of the needs of Asian and Middle Eastern migrant students in terms of their literacy level, schooling history and cultural background make them unsuccessful in the educational system of destination countries (Derderian, Aghajanian \& Cong, 2012), (Khoir, Du, \& Koronios, 2014). Most European countries have a strong religious identity and their own languages. The intergenerational educational mobility problems also have different outcomes for these immigrants (Cuaresma et al., 2015). In addition to these barriers to moving abroad, it appears that the personality of potential migrants (linguistic, nationalistic and risk averse) matters, as well as the lack of social networks abroad (van Dalen \& Henkens, 2012). Thus, Oceania has a positive and significant relationship with educational attainment; these migrants are predominately from Australia and surrounding countries.

It appears in Models 3 and 4 of Table 3 that Africans are younger than migrants from other regions. Over the past decade, the population of the African continent has grown by cc. 30 million and more than 680 million inhabitants live in extreme poverty and insecure living conditions, which force them to be migrants. These tendencies are well established and lead us to believe that the Sub-Saharan region has probably the highest potential for immigration into the OECD than any other region of the world (Kohnert, 2007). In parallel, European and North American migrants seem to be older than others are.

According to the results of our estimations, there is a positive correlation between the age and educational attainment of immigrants. Not surprisingly, older migrants are more educated. In the other words, their education level increases with age. The H9 hypothesis can be accepted. Hence, the number of immigrants, in terms of their age and educational level, crucially shape the economic impact of immigration. Younger migrants appear to be more disadvantaged in educational achievements than older migrants (Jones, 1981). For instance, children's educational background can be different from that of the destination countries' education system. In this case, adaptation for young migrants can be harder than for older migrants. Thus, offering permanent residency, and social security provision fosters greater flows of high-skilled workers and improves the skill selectivity of immigrant flows (Czaika \& Parsons, 2017).

Nevertheless, female migrants are less likely to be educated than male migrants. The H7 hypothesis is accepted. Norton \& Tomal (2009) also found a significant negative relationship between female educational attainments and the extent of religious belief, with similar gender gap results. Meanwhile, the H10 hypothesis should be rejected. There is no significant linkage between age and gender in our model. Although migration is largely beneficial, gender and racial discrimination and gender-specific vulnerabilities can both authorize and pressurize the rights and opportunities of migration (Fleury, 2016). Meanwhile, women's return to education through marriage has declined while men's financial gain through marriage has increased greatly (Kim \& Sakamoto, 2017).

In Models 3 and 4, foreign-born migrants are negatively correlated with age, although the value of the coefficient is not high. In these cases, foreign-born migrants seem to be younger than native-born migrants. The H11 hypothesis is accepted. Not surprisingly, the old migrate less than the young within their origin countries (Zaiceva, 2014). Consequently, thanks to the tendency towards an increasingly foreign-born population in the developed host countries, the aging problems of their societies will be moderated in the forthcoming decades. Thus, the H8 hypothesis is not accepted. There is no correlation between place of birth and the educational level of migrants. 
One of the main limitations of our estimations also needs to be emphasized, because these findings are able to demonstrate only one empirical aspect of migration differences. Meanwhile, other determinants, which might affect regional differences, such as adaptability, the integration rate in the host country, etc. have been not included due to restricted access to data, so the validity of our conclusions is limited by the bias caused by the exclusion of these variables and regression methods. Moreover, we believe that a better understanding of the characteristics of migration is a potentially important element in the success of government policies to resolve the negative outcomes of forthcoming migration disasters. Hence, in this empirical approach, further research could provide fruitful and substantial opportunities for future exploration.

\section{Discussions and implications}

The main purpose of this research is to demonstrate the role of regional differences of migration. According to the results, we can claim that the educational attainment, age, sex and the place of birth of migrants relate differently to their region of birth. More precisely, African, Asian and European migrants tend to be less educated than others are, and European or North American migrants are significantly older than other groups. African migrants tend to be male, while European and South and Central Americans tend to be female. Asian, South and Central American migrants are significantly more likely to be foreign-born. Moreover, migrants that are more educated are older than the less skilled, and female migrants are less educated than males in the OECD countries examined. Thus, foreign-born migrants seem to be younger than native migrants. At the same time, this research shows that the educational attainment, age, gender and place of birth of migrants are related to regional differences.

There are many reasons behind these phenomena. For instance, migrants generally move from rural to urban areas. As a cultural context, most rural regions pay more attention to male than to female education. When females move to another country as migrants, it is usually related to their marital status. Hence, they do not have any resilient educational background, which is one of the main reasons why female migrants are less educated than their male counterparts. Thus, based on the literature (Čajka, Jaroszewicz, \& Strielkowski, 2014), male migrants are more likely to move long distances than women are.

In order to reduce gender and educational inequalities among immigrants in the destination countries it seems to worth improving intergenerational educational mobility. In our opinion, language-skill oriented programs could efficiently support migrants to become more highly skilled. Consequently, gender differences can be eliminated more easily than they would be without this provision. From this perspective, the analysis suggests that policymakers should reduce 'skill-gaps' by motivating low-skilled migrants to learn more. Moreover, the integration of such individuals should not be seen as resulting in any unfavourable changes in criminal statistics, working conditions, unemployment or labour discrimination (Dajnoki, Máté, Fenyves, \& Kun, 2017).

In aging OECD countries families prefer to have fewer children and concentrate on their careers (Arltová, Smrčka, Vrabcová, \& Schönfeld, 2016). In these individualistic nations, communication is mostly verbal, whereas in collectivist cultures it is implicit. Most African and Asian countries have a collectivist culture, in which people are more likely to live in patriarchal families and emphasize the needs and goals of the group as a whole, rather than focusing on the needs, wishes and rights of each individual. For example, workers who live in this type of culture might strive to sacrifice their own happiness for the greater good of the group. Those from individualist cultures, on the other hand, may feel that their own wellbeing and goals carry a greater weight. These cultural differences are pervasive and can influence many aspects of life, including labour skills, learning abilities and the conduct of 
business activities, etc. (Kim \& Markus, 1999). Therefore, the destination countries should focus on considering migrants' cultural background as well, to manage the homogeneity of the migrants when launching some of these improvement programs. Hopefully, these rigorous educational policies will give more benefits than disadvantages to the destination countries.

The educational attainment in the destination countries is another crucial element in determining migrants' performance in the labour market (Oláh et al., 2017). However, the educational skills immigrants bring with them may not be easily transferable to the host countries' labour market due to their language deficiencies. A highly skilled immigrant is unlikely to command the same wage as a native-born worker with the same educational background, at least in the first years after their arrival (Dustmann \& Glitz, 2011). Consequently, it appears that migrating at a younger age has more disadvantages than at an older age (Jones, 1981). Moreover, the young children of immigrants commonly have more limited linguistic skills than older migrants (Hunt, 2012). Essentially, the older the immigrant, the higher the level of opportunity costs associated with schooling due to investments made in the origin country. These factors make migration related to educational attainment more profitable for older migrants when compared to younger migrants (BChiswick \& DebBurman, 2004).

\section{Conclusions}

One-size-fits-all solutions cannot be drawn from these results when attempting to identify the best policy practices in the context of the growing recognition of migration problems. These responses need to be adapted to the diverse environments in which modern migration still occurs. Our evidence suggests it is worth monitoring the role of migration differences across regions and individual countries to provide better support over time. The establishment of international legal standards relating to modern slavery in different regions is also another critical element in broader prevention and protection policy efforts. A multifaceted response addresses the array of economic, social, cultural and legal forces that contribute to vulnerability and enable abuses (ILO, 2017).

There is also additional evidence that different regions and countries seem to follow different policies and norms for the admission of migrants. Public interventions, both before and on the arrival of immigrants, primarily aim at influencing the pool of immigrants in the host country; these are referred to as selection and settlement policies. Other types of public policies and programs that aim to improve the economic and social outcomes of immigrants after their arrival and settlement in the host country are introduction programs, language training, active labour market programs, and anti-discrimination policies.

According to Máté, Sarihasan, \& Dajnoki (2017) one of the best solutions is to allow labour market institutions to solve a large element of the unexplained characteristics of migration differences. For instance, a decrease in unemployment benefits (UBs), and reduced power of (trade) unions could be a fruitful way to enhance the integration for both types of employed migrants. Furthermore, less strict employment protect legislation (EPL), lower minimum wages and more supported active labour market programmes (ALMPs) seem to increase the labour adaptability of native-born migrants. In practice, the first solution is to allow for contracts that are more flexible, the second is to emphasize the crowding out effects of minimum wages on employability and highlight the need for immigrant training programmes in the initial years.

In our opinion, exclusive regional policies by themselves cannot adequately deal with the new challenges posed by contemporary migration, since intra-regional migration asymmetries, such as the gap between migration pressure and the absorption of migrants are often too wide to be limited or managed within the borders of each geographic region (Nita et. 
$a l, 2017)$. These approaches vary significantly, and range between allowing inclusive free movement on the one hand, and conceding more limited rights only to categories of migrants of a certain educational level, and for specific jobs, on the other. Therefore, forthcoming migration governance programs that aim to facilitate the labour market integration of migrants should also take into consideration their regional characteristics in order to facilitate the labour market integration of migrants.

\section{Acknowledgements}

This work supported by the Horizon 2020 Working Programme (H2020-SC6MIGRATION-2018-2019-2020) of the European Commission. The authors are grateful for the financial support provided to carry out this research.

\section{References}

Arltová, M., Smrčka, L., Vrabcová, J., \& Schönfeld, J. (2016). The Ageing of the Population in Developed Countries - the Economic Consequences in the Czech Republic. Economics \& Sociology, 9(2), 197-219. https://doi.org/10.14254/2071-789X.2016/9-2/14

Aubry, A., Burzyński, M., \& Docquier, F. (2016). The welfare impact of global migration in OECD countries. Journal of International Economics, 101, 1-21. https://doi.org/10.1016/J.JINTECO.2016.03.005

Beck, A., Corak, M., \& Tienda, M. (2012). Age at Immigration and the Adult Attainments of Child Migrants to the United States. Annals of the American Academy of Political and Social Science, 643(1), 134-159. https://doi.org/10.1177/0002716212442665

Biswas, T., McHardy, J., \& Nolan, M. A. (2005). Inter-regional Migration: the UK Experience. Sheffield Economic Research Paper Series, (January), 1-32.

Bodvarsson, Ö. B., \& Van den Berg, H. (2013). The Economics of Immigration. New York, NY: Springer New York. https://doi.org/10.1007/978-1-4614-2116-0

Borjas, G. J., Bronars, S. G., \& Trego, S. J. (1992). Self-Selection and Internal Migration in the United States. Journal of Urban Economics, 32, 159-185.

Burzynski, M., Docquier, F., \& Rapoport, H. (2018). The Changing Structure of Immigration to the OECD: What Welfare Effects on Member Countries? IZA Discussion Papers. Retrieved from https://ideas.repec.org/p/iza/izadps/dp11610.html

Čajka, P., Jaroszewicz, M., \& Strielkowski, W. (2014). Migration incentives and flows between Belarus, Moldova, Ukraine and the European Union: A forecasting model. Economics and Sociology, 7(4), 11-25. https://doi.org/10.14254/2071-789X.2014/7-4/1

Castles, S. (2013). The Forces Driving Global Migration. Journal of Intercultural Studies, 34(2), 122-140. https://doi.org/10.1080/07256868.2013.781916

Chiswick, B., \& Miller, P. (2014). Handbook of the Economics of International Migration, 1 SET. Elsevier Science.

Chiswick, B. R., \& DebBurman, N. (2004). Educational attainment: analysis by immigrant generation. Economics of Education Review, 23(4), 361-379. https://doi.org/DOI 10.1016/j.econedurev.2003.09.002.

Cox, D. R. (1958). The Regression Analysis of Binary Sequences. Journal of the Royal Statistical Society. Series B (Methodological). WileyRoyal Statistical Society. https://doi.org/10.2307/2983890.

Cuaresma, J. C., Huber, P., Oberdabernig, D., \& Raggl, A. (2015). Migration in an ageing Europe: What are the challenges? (No. 79). WWWforEurope.

Czaika, M., \& Parsons, C. R. (2017). The Gravity of High-Skilled Migration Policies. Demography, 54(2), 603-630. https://doi.org/10.1007/s13524-017-0559-1 
Dajnoki, K., Máté, D., Fenyves, V., \& Kun, A. I. (2017). Deconstructing attitudes towards immigrant workers among Hungarian employees and higher education students. Sustainability, 9(9). https://doi.org/10.3390/su9091639

Derderian-aghajanian, A., \& Cong, W. C. (2012). How Culture Affects on English Language Learners ' ( ELL's ) Outcomes, with Chinese and Middle Eastern Immigrant Students. International Journal of Business and Social Sciences, 3(5), 172-180.

di Giovanni, J., Levchenko, A. A., \& Ortega, F. (2015). A global view of cross-border migration. Journal of the European Economic Association, 13(1), 168-202. https://doi.org/10.1111/jeea.12110

Dumont, J.-C., \& Lamaitre, G. (2005). Counting immigrants and expatriates in OECD countries. Trends in International Migration 2004, (1), 115-149. https://doi.org/10.1787/eco_studies-v2005-art3-en

Dustmann, C., \& Glitz, A. (2011). Migration and Education. Handbook of the Economics of Education (Vol. 4). https://doi.org/10.1016/B978-0-444-53444-6.00004-3

Findlay, A. M., \& Mulder, C. H. (2015). Scoping the Future of 'Population, Space and Place.' Population, Space and Place, 21(8), 689-691. https://doi.org/10.1002/psp.2000

Fleury, A. (2016). Understanding Women and Migration: A Literature Review (Working Paper 8.).

Flisi, S., Meroni, E. C., \& Vera-Toscano, E. (2016). Educational outcomes and immigrant background. https://doi.org/10.2791/026577

Fournier, S. F. (1989). The Link Between Trade, Migration, and Regional change. Massachusetts Institute of Technology.

Greenwood, M. J. (1997). Internal migration in developed countries. In Handbook of Population and Family Economics (Vol. 1, Part B, pp. 647-720). Elsevier.

Hair, J. F. (2010). Multivariate data analysis. Prentice Hall.

Hunt, J. (2012). The impact of immigration on the educational attainment of natives. Nber $\begin{array}{llll}\text { Working } & \text { Paper } & \text { Series, } & \text { No. }\end{array}$ https://doi.org/10.1017/CBO9781107415324.004

Iceland, J. (2017). Race and ethnicity in America. Oakland California: University of California Press.

ILO. (2017). Global estimates of modern slavery: forced labour and forced marriage.

Jandová, M., \& Paleta, T. (2015). Gravity models of internal migration - The Czech case study. Review of Economic Perspectives, 15(1), 3-14. https://doi.org/10.1515/revecp2015-0008

Jones, F. E. (1981). Age at immigration and educational attainment. Canadian Review of Sociology/Revue Canadienne de Sociologie, 18(3), 393-405. https://doi.org/10.1111/j.1755-618X.1981.tb00062.x

Kainth, G. (2009). Push and pull factors of migration: A case of Brick Kiln industry of Punjab State (No. 30036). Asian-Specific Journal of Social Sciences. https://doi.org/http://www.socialsciences-ejournal.org

Khoir, S., Du, J. T., \& Koronios, A. (2014). Study of Asian Immigrants' Information Behaviour in South Australia: Preliminary Results. IConference 2014. https://doi.org/10.9776/14316

Kim, C. H., \& Sakamoto, A. (2017). Women's Progress for Men's Gain? Gender-Specific Changes in the Return to Education as Measured by Family Standard of Living, 1990 to 2009-2011. Demography, 54(5), 1743-1772. https://doi.org/10.1007/s13524-017-0601-3

Kim, H., \& Markus, H. R. (1999). Deviance or uniqueness, harmony or conformity? A cultural analysis. Journal of Personality and Social Psychology, 77(4), 785-800. https://doi.org/10.1037/0022-3514.77.4.785

Kohnert, D. (2007). African Migration to Europe: Obscured Responsibilities and Common 
Misconceptions, (May), 24. https://doi.org/www.giga-hamburg.de Electronic

Koser, K., \& Salt, J. (1997). The geography of highly skilled international migration. International Journal of Population Geography, 3(4), 285-303. https://doi.org/10.1002/(SICI)1099-1220(199712)3:4<285::AID-IJPG72>3.0.CO;2-W

Máté, D., Sarihasan, I., \& Dajnoki, K. (2017). The relations between labour market institutions and employment of migrants. Amfiteatru Economic, 19(46), 806-820.

McInnis, M. (1971). Age, education and occupation differentials in interregional migration: some evidence for Canada. Demography, 8(2), 195-204. https://doi.org/10.2307/2060609

Millington, J. (2000). Migration and Age: The Effect of Age on Sensitivity to Migration Stimuli. Regional Studies, 34(6), 521-533. https://doi.org/10.1080/00343400050085648

Mueser, P. R. (1989). Measuring the Impact of Locational Characteristics on Migration: Interpreting Cross-Sectional Analyses. Demography, 26(3), 499. https://doi.org/10.2307/2061609

Nita, S., Pécoud, A., De Lombaerde, P., Neyts, K., \& Gartland, J. (2017). Migration, Free Movement and Regional Integration. (Sonja Nita (Schröder) Antoine Pécoud Philippe De Lombaerde KateNeyts Josh Gartland Paulde Guchteneire, Ed.). Retrieved from http://cris.unu.edu/migration-free-movement-and-regional-integration

Norton, S. W., \& Tomal, A. (2009). Religion and female educational attainment. Journal of Money, Credit and Banking, 41(5), 961-986. https://doi.org/10.1111/j.15384616.2009.00240.x

OECD. (2017). Foreign-born population (indicator). https://doi.org/doi: 10.1787/5a368e1b-en

OECD. (2018). Database on Immigrants in OECD and non-OECD Countries: DIOC - OECD. Retrieved January 12, 2018, from http://www.oecd.org/els/mig/dioc.htm

Oláh, J., Halasi, G., Szakály, Z., Popp, J., \& Balogh, P. (2017). The impact of international migration on the labour market - A case study from Hungary. The Amfiteatru Econmic, 19(46), 790-805.

Ozgur, E.M and Deniz, A. (2014). a Migration System Formation Based on Tourism. Aegean Geographical Journal, 23, 1-18.

Philip, L., Macleod, M., \& Stockdale, A. (2013). Retirement Transition, Migration and Remote Rural Communities: Evidence from the Isle of Bute. Scottish Geographical Journal, 129(2), 122-136. https://doi.org/10.1080/14702541.2013.783616

Quinn, M. A., \& Rubb, S. (2005). The Importance of Education-Occupation Matching in $\begin{array}{llll}\text { Migration Decisions. } & \text { Demography, }\end{array}$ https://doi.org/10.1353/dem.2005.0008

Rahmandoust, M. (2011). Iranian Entrepreneurs in Malaysia: Their Migration Reasons Iranian Entrepreneurs in Malaysia: Their Migration Reasons. The Middle East, 13(9), 2075-2081.

Ravenstein, E. G. (1885). The Laws of Migration. Journal of the Statistical Society of London.Tun, 48(2), 167-235.

Reed, H. E., \& Andrzejewski, C. S. (2010). The New Wave of African Immigrants in the United States. Population Association of American 2010 Annual Meeting.

Rephann, T. J., \& Vencatasawmy, C. P. (2000). Determinants of the Spatial Mobility of Immigrants: Evidence from Sweden. The Review of Regional Studies, 30(2), 189-213. Retrieved from https://ideas.repec.org/a/rre/publsh/v30y2000i2p189-213.html

Rosen, S. (1974). Hedonic Prices and Implicit Markets: Product Differentiation in Pure Competition. Journal of Political Economy, 82(1), 34-55. https://doi.org/10.1086/260169

Schwartz, A. (1976). Migration, Age, and Education. Journal of Political Economy, 84(4, Part 1), 701-719. https://doi.org/10.1086/260472

Tiebout, C. M. (1956). A Pure Theory of Local Expenditures. Journal of Political Economy, 64(5), 416-424. https://doi.org/10.1086/257839 
UN. (2017). United Nations Statistics Division - Classifications Registry, ISIC Rev. 4.

UNESCO. (2011). International Standard Classification of Education (UIS/2012/INS/10/REV). UNESCO Institute of Statistics.

United Nations. (2017). International Migration Report 2017.

van Dalen, H. P., \& Henkens, K. (2012). Explaining low international labour mobility: the role of networks, personality, and perceived labour market opportunities. Population, Space and Place, 18(1), 31-44. https://doi.org/10.1002/psp.642

Williams, A. M., Jephcote, C., Janta, H., \& Li, G. (2018). The migration intentions of young adults in Europe: A comparative, multilevel analysis. Population, Space and Place, 24(1), e2123. https://doi.org/10.1002/psp.2123

Zaiceva, A. (2014). The impact of aging on the scale of migration (99). IZA Workd of Labor. https://doi.org/doi: 10.15185/izawol.99 


\section{Appendix}

Table A.1. Descriptive statistics of the examined variables

\begin{tabular}{lccccccccc}
\hline & Minimum & Maximum & Mean & Std. Deviation & \multicolumn{2}{c}{ Skewness } & \multicolumn{2}{c}{ Kurtosis } \\
\cline { 2 - 9 } & Statistic & Statistic & Statistic & Statistic & Statistic & Std. Error & Statistic & Std. Error \\
\hline Age & 1 & 7 & 4.13 & 1.863 & -.013 & .003 & -1.116 & .006 \\
\hline Edu & 1 & 6 & 3.35 & 1.667 & .095 & .003 & -1.239 & .007 \\
\hline DSex & 1 & 2 & 1.50 & .500 & -.002 & .003 & -2.000 & .006 \\
\hline DFborn & 0 & 1 & .99 & .098 & -9.988 & .003 & 97.751 & .006 \\
\hline DAfrica & 0 & 1 & .23 & .423 & 1.266 & .003 & -.398 & .006 \\
\hline DAsia & 0 & 1 & .23 & .421 & 1.281 & .003 & -.359 & .006 \\
\hline DEurope & 0 & 1 & .30 & .458 & .875 & .003 & -1.234 & .006 \\
\hline DN_America & 0 & 1 & .02 & .127 & 7.635 & .003 & 56.298 & .006 \\
\hline DOceania & 0 & 1 & .05 & .220 & 4.084 & .003 & 14.683 & .006 \\
\hline DS\&C_America & 0 & 1 & .16 & .370 & 1.822 & .003 & 1.318 & .006 \\
\hline
\end{tabular}

Source: own compilation based on (OECD, 2018)

Table A.2. Pearson correlation matrix of the examined variables

\begin{tabular}{|c|c|c|c|c|c|c|c|c|c|}
\hline & Edu & Age & DSex & DFborn & DAfrican & DAsian & DEuropean & DN_A. & DOceanian \\
\hline Edu & 1.000 & & & & & & & & \\
\hline Age & $0.072 * * *$ & 1.000 & & & & & & & \\
\hline DSex & $-0.01 * *$ & 0.001 & 1.000 & & & & & & \\
\hline DFborn & $0.000^{* * *}$ & $-0.009 * * *$ & 0.000 & 1.000 & & & & & \\
\hline DAfrica & $-0.009 * * *$ & $-0.022 * * *$ & $-0.01 * * *$ & $0.054 * * *$ & 1.000 & & & & \\
\hline DAsia & 0.000 & $-0.01 * * *$ & 0.000 & $0.05 * * *$ & $-0.3 * * *$ & 1.000 & & & \\
\hline DEurope & $-0.004 * * *$ & $0.034 * * *$ & $0.004 * * *$ & $-0.114 * * *$ & $-0.362 * * *$ & $-0.361^{* * *}$ & 1.000 & & \\
\hline DN_America & $0.004 * * *$ & $0.009 * * *$ & 0.000 & $-0.016 * * *$ & $-0.072 * * *$ & $-0.071 * * *$ & $-0.086 * * *$ & 1.000 & \\
\hline DOceania & $0.01 * * *$ & $-0.003^{* *}$ & 0.001 & $-0.006^{* * *}$ & $-0.126^{* * *}$ & $-0.126 * * *$ & $-0.152 * * *$ & $-0.03 * * *$ & 1.000 \\
\hline
\end{tabular}

Source: own compilation based on (OECD, 2018)

Notes: Letters in the upper index refer to significance: ***: significance at 1 per cent, **: 5 per cent, *: 10 per cent. P-values without an index mean that the coefficient is not significant even at the 10 per cent level. 